\title{
Acarreo de divisas y costo de las reservas internacionales en México
}

\author{
Carlos A. Rozo y Norma Maldonado ${ }^{1}$
}

\section{Resumen}

Las estrategias nacionales a las que ha llevado la crisis financiera mundial para impulsar el crecimiento económico han inducido a desequilibrios monetarios entre los países industriales y las economías emergentes. Al implementar políticas monetarias ultraexpansivas, los primeros empujan a la baja las tasas de interés, mientras que al introducir políticas monetarias más restrictivas, las segundas incrementan esas tasas de interés, generándose así un creciente acarreo de divisas. Surgen entonces condiciones de vulnerabilidad por la salida súbita de estos capitales o por los altos costos que implica protegerse contra tal eventualidad por medio de la acumulación de reservas. En este trabajo se calcula que la acumulación de reservas ha tenido un costo promedio anual del 1,83\% del PIB entre 2008 y 2014, lo que lleva a concluir que la libre movilidad de capitales que practican las autoridades mexicanas entraña un alto costo para cumplir con las reglas de la globalización financiera.

\section{Palabras clave}

Movimientos de capital, divisas, mercados de divisas, reservas monetarias, costos, política monetaria, México

\section{Clasificación JEL}

F31, F32, F38

\section{Autores}

Carlos Antonio Rozo Bernal es Profesor Titular de tiempo completo, nivel C, del Departamento de Producción Económica de la Universidad Autónoma Metropolitana de México. Correo electrónico: rozo@correo.xoc.uam.mx.

Norma Maldonado es Ayudante de Investigación del Departamento de Producción Económica de la Universidad Autónoma Metropolitana de México. Correo electrónico: normamc_27@hotmail.com. 



\section{Introducción}

Las estrategias nacionales a las que ha llevado la crisis financiera mundial para impulsar el crecimiento económico han inducido a desequilibrios monetarios entre los países industriales y las economías emergentes. Al implementar políticas monetarias ultraexpansivas, los países industriales empujan a la baja las tasas de interés, con lo cual reducen el valor de sus monedas al tiempo que proporcionan más competitividad a sus sectores exportadores. Los países emergentes, con el propósito de atraer capitales, introducen políticas monetarias más restrictivas, que incrementan las tasas de interés. Estas políticas contrapuestas han llevado a diferenciales significativos en las tasas de interés, que atraen los flujos de capital hacia los mercados emergentes.

Se ha suscitado así un amplio y creciente acarreo de divisas (carry trade) que da energía y fortaleza a lo que Burnside, Eichenbaum y Rebelo (2011) califican como una de las más viejas y populares estrategias de especulación con divisas. Este acarreo genera cuantiosas ganancias para los capitales golondrina de corto plazo, pero compromete el bienestar en los mercados emergentes al crear condiciones de vulnerabilidad por la salida súbita de estos capitales o por los altos costos que implica protegerse contra tal eventualidad por medio de la acumulación de reservas.

La relevancia de este acarreo de divisas obligó al Fondo Monetario Internacional (FMI) a reconocer la validez de las reacciones de algunos de los gobiernos de países emergentes para defenderse contra estas presiones del capital de corto plazo con políticas de control transfronterizo. Se reconoció de este modo que los países emergentes no tenían por qué pagar los platos que los países más desarrollados habían roto. El FMI aceptó que en ciertas circunstancias y ciertas condiciones estos países estaban en el derecho de recurrir al uso de políticas para enfrentar los riesgos provocados por las entradas de capitales especulativos. Así se admitió que la regulación de las corrientes de capital transfronterizas es legítima y puede ser útil como parte de una estrategia macroeconómica destinada a evitar que estos capitales incidan sobre el valor de la moneda local o a mitigar estas repercusiones.

México es uno de los mercados emergentes cuyo tipo de cambio ha experimentado fuertes presiones por estos flujos de capital. Otros países que han corrido una suerte semejante -y en algunos casos con presiones mayores - han sido, entre otros, el Brasil, Chile, el Perú, la República de Corea, Tailandia, la India y Colombia. La diferencia entre México y los demás países afectados responde a la actitud de las autoridades mexicanas, que no consideran prudente ni necesario intervenir para controlar el fortalecimiento del peso, como sí lo han hecho los otros países. Las autoridades monetarias mexicanas se aferran a descartar la apreciación del peso como un factor negativo para la economía, por lo que no es necesario recurrir a controles o, como los llama el FMI, medidas de gestión del tipo de cambio. Esta postura oficial se sustenta en el argumento de que el sistema financiero mexicano se encuentra blindado contra una súbita salida de capitales por la acumulación de altos niveles de reservas internacionales y la contratación de una Línea de Crédito Flexible (LCF) con el FMI.

El propósito de este trabajo es entender la lógica en virtud de la cual las autoridades mexicanas consideran positivo lo que las autoridades de otros países estiman perjudicial para sus economías. Se postula la hipótesis de que la libre movilidad de capitales que practican las autoridades mexicanas es negativa para el bienestar de los mexicanos debido al alto costo que se paga por acumular reservas internacionales. Para demostrar este planteamiento, en las secciones II, III y IV se examinan las bases del debate sobre la necesidad de controles cambiarios que llevó al FMI a aceptar que cierto tipo de medidas, en ciertas condiciones, son positivas para los países emergentes y en desarrollo, y a continuación se analiza la evolución del tipo de cambio y su relación con la política monetaria que dio lugar al superpeso mexicano. En las siguientes tres secciones (V, VI y VII) se pasa revista a la magnitud y al rendimiento de los flujos de capital, y a la prevalencia de los capitales de corto plazo. Luego, en la sección VIII, se estima el costo del blindaje financiero y finalmente se presentan las conclusiones. 


\section{Acarreo de divisas y proteccionismo cambiario}

La necesidad de recuperar la dinámica de crecimiento perdida a raíz de la Gran Recesión ha llevado a las economías industriales, pero principalmente a la estadounidense, a una política monetaria laxa que ha inducido a una disminución a cero de la tasa de interés de referencia. El bajo rendimiento de las inversiones financieras en estas economías ha incentivado el traslado de inmensas cantidades de capital hacia economías con mayores tasas de rendimiento. Para mejorar su rentabilidad, los inversores financieros han inundado de liquidez los mercados de dinero de los países emergentes con flujos privados de cartera que han entrado a estos países desde 2009.

Estos flujos han tenido efectos negativos en la estabilidad de los tipos de cambio. En los países industriales la tendencia general ha sido hacia la depreciación de sus monedas, mientras que en los mercados de países emergentes las monedas han tendido generalmente a su apreciación. Estos movimientos cambiarios han proporcionado ventajas comerciales a los primeros, al tiempo que perjudican la competitividad de los segundos. Ante estos desequilibrios gestados por la política monetaria de los países industriales, la respuesta de los países emergentes tiende hacia la protección de sus mercados, lo que marca un nuevo hito en el desarrollo de la crisis mundial al abrirse la ventana del proteccionismo cambiario. Apuntan Gallagher (2011a) y Rodrik (2010) que, con este enfrentamiento, la economía internacional se aproxima al fin de una era en las finanzas internacionales, la era de la libre movilidad de capitales especulativos.

El amplio diferencial de tasas de interés entre el Norte y el Sur ha creado oportunidades para apostar al acarreo de divisas, es decir, la estrategia que consiste en pedir prestados recursos denominados en una divisa con tasas de interés bajas - divisa fondeadora-, para invertirlos en valores financieros en las divisas de países que ofrezcan un rendimiento mayor - divisa inversora- (Burnside, Eichenbaum y Rebelo, 2011; Clarida, Davis y Pedersen, 2009). La operación se lleva a cabo con el propósito de obtener una ganancia fiduciaria que es reforzada por la posible apreciación de la divisa inversora, la que paga la mayor tasa de interés (Banco de México, 2010). A pesar del riesgo que existe, la evidencia tiende a demostrar que esta actividad es rentable, como argumentan Brunnermeier, Nagel y Pedersen (2008), y Jordá y Taylor (2009).

En la teoría de la paridad de los tipos de interés no cubierta se postula que en una economía sin fricciones y neutral al riesgo, el acarreo de divisas no es rentable debido a que la ganancia derivada del diferencial de tasas de interés es compensada por una depreciación proporcional de la divisa inversora. Los flujos de capital que entran al país producen una apreciación inmediata de la divisa por una sobrerreacción del mercado, pero posteriormente esta apreciación se resuelve y la divisa termina por depreciarse (Fama, 1984; Dornbusch, 1976). Lo que ocurre en la operación de los mercados es que, al persistir en el tiempo, el acarreo de divisas viola estos postulados de la teoría, ya que la divisa inversora se mantiene en una tendencia de apreciación, lo que hace que esta actividad sea rentable.

Esta problemática, denominada el "problema del peso" (forward premium puzzle), está asociada al riesgo de quiebra debido a que los tipos de cambio suben por la escalera y bajan por el ascensor, lo que implica que en el largo plazo esta dinámica puede llevar a una "burbuja cambiaria"2. La prima es el precio del riesgo de quiebra.

El rendimiento de los activos en que invierten los especuladores tiene dos factores básicos: una tasa de ganancia media positiva y un sesgo (skewness) negativo. La ganancia ocurre en reconocimiento de la liquidez que el acarreo proporciona a la economía inversora, mientras que el sesgo negativo deriva de la exposición de la divisa inversora al riesgo de quiebra, por los movimientos en dirección opuesta del tipo de cambio al contado y del tipo de cambio a futuro o tipo de cambio esperado. El hecho que cabe enfatizar es que los diferenciales positivos de tasas de interés están asociados a

\footnotetext{
2 Véase una revisión bibliográfica sobre el tema en Engel (1996).
} 
una condición de sesgo negativo de los movimientos de tipos de cambio, lo que significa que los rendimientos del acarreo de divisas conllevan implícitamente un riesgo de quiebra (Brunnermeier, Nagel y Pedersen, 2008, pág. 4). Este riesgo ocurre en función de las respuestas asimétricas de los inversores a movimientos en el tipo de cambio esperado. Cuando los cambios llevan a pérdidas, estas se amplifican por las dificultades que pueden tener los especuladores para obtener fondeo y por la urgencia en deshacerse de los activos. Este hecho induce a una caída en los precios de los activos, lo que agudiza los problemas de fondeo y de volatilidad.

El problema del peso tiene connotaciones teóricas pertinentes sobre la forma en que funcionan los mercados financieros internacionales al sugerir la invalidez del concepto de expectativas racionales. Además, indicaría que el diferencial en las tasas de interés es una guía poco relevante para una eficiente asignación de recursos por la volatilidad que imprime a movimientos futuros en el tipo de cambio. Se tiene, entonces, un ejemplo significativo de ineficiencias del mercado, lo que permite sugerir la necesidad de intervención gubernamental en el mercado de cambios.

\section{Consecuencias del acarreo}

Este acarreo de capital no es neutro sobre el valor de la divisa inversora: impulsa su apreciación, lo que constituye un fracaso de la hipótesis de mercados eficientes. El argumento clave de esta tendencia de apreciación se sustenta en que los grandes volúmenes de capital de corto plazo tienden a ser procíclicos, es decir, ingresa demasiado dinero en la fase de crecimiento del ciclo económico y sale demasiado dinero en la fase descendente (Gallagher, 2011a y 2011b). Estas corrientes generan costos y desequilibrios en la relación entre el equilibrio interno y externo de los países receptores.

No queda del todo claro cómo ocurren estos equilibrios al considerar el intenso debate sobre cuál es el régimen cambiario más apropiado para que la política cambiaria cumpla cabalmente con los objetivos de equilibrio y asignación de recursos en un contexto de globalización. No es evidente si el tipo de cambio debe ser totalmente fijo o totalmente flexible, o alcanzar un nivel intermedio entre estos extremos, como expone Frankel (2003). No menos relevante en este debate ha sido el hacer evidente que las autoridades nacionales declaran oficialmente funcionar bajo un régimen de flotación cuando de facto practican uno de tipo fijo o controlado, como Calvo y Reinhart (2000) atinadamente expresan en su concepto del "miedo a flotar". Tampoco hay certidumbre de que las opciones extremas - total rigidez o total flexibilidad - lleven a que el mercado determine benignamente el nivel del tipo de cambio apropiado para un país en particular. De lo que no quedan dudas es que bajo el régimen de tipos de cambio flotantes, al que han recurrido los mercados emergentes desde mediados de la década de 1990, este acarreo ha crecido astronómicamente.

En el debate que se ha suscitado en torno del proteccionismo cambiario, el argumento de Ffrench-Davis (2010) sobre el "error neoliberal" nos parece una propuesta atinada. El error consiste en la creencia de que cualquier intervención cambiaria va en contra del mercado, cuando es necesario distinguir entre dos tipos de mercado. En el enfoque ortodoxo neoliberal monetarista contemporáneo, el mercado que se busca favorecer es el mercado de crédito especulativo de los operadores de corto plazo que solo persiguen maximizar sus rentas. En esta lógica, el tipo de cambio responde más a variaciones en la cuenta de capitales que a variaciones en la balanza comercial o en la cuenta corriente, lo que significa que el tipo de cambio se convierte en un activo financiero, como postuló Keynes (2003).

En un enfoque correcto, el mercado apropiado es el de la producción de bienes comercializables y no comercializables en un contexto de innovación y cambio tecnológico. Los equilibrios buscados y las asignaciones adecuadas deben ser los que favorezcan la creación de riqueza productiva, la que satisface las necesidades sociales. 
El error neoliberal es el factor responsable de la extrema volatilidad de los tipos de cambio nominal, pues su nivel responde más a variaciones en los flujos de capital que a los flujos de mercancías y de servicios. Así, con un tipo de cambio flexible se está expuesto a variaciones procíclicas por las acciones de fondos externos de inversión de cartera y, en consecuencia, el tipo de cambio se vuelve volátil a raíz de las condiciones impuestas por operadores financieros y trae aparejados efectos negativos para la economía nacional, como los anotados por Ffrench-Davis, a saber: i) distorsiones en la evaluación de proyectos para la asignación de recursos; ii) una mayor promoción de inversiones especulativas que de inversiones productivas; iii) el desplazamiento de la producción de bienes transables importables, y iv) una merma en la generación de valor agregado de las exportaciones.

Estos efectos pueden distorsionar una estrategia de desarrollo liderada por la producción de exportaciones no tradicionales que generan externalidades e interactúan con las pequeñas y medianas empresas (pymes). Para este propósito, argumenta Ffrench-Davis, es mejor el uso de regímenes intermedios de flotación sucia o de bandas móviles, ya que moverse hacia el mercado correcto requiere una intervención en los mercados que sea coherente y selectiva. En este contexto, es evidente que los movimientos de capital que aprecian el tipo de cambio tienden a restar competitividad a las economías nacionales, lo que contrae el crecimiento de las exportaciones e incentiva el aumento de las importaciones.

En consecuencia, los países emergentes tendrían razón al diseñar e instrumentar políticas macroprudenciales para controlar los efectos negativos que puede tener el acarreo de divisas. La respuesta ha estado orientada a elaborar estrategias destinadas a inhibir la entrada de estos capitales especulativos para evitar que sus monedas se aprecien. La aplicación de estos esquemas y las respuestas a tales acciones han llevado a lo que se denomina un ambiente de "guerra de divisas" (Pérez, 2010): una pugna por obtener un lugar más competitivo en el comercio internacional. Joseph Stiglitz (2010) ha apuntado lo negativo que puede ser esta guerra, pues todos los países pueden ser perdedores, por lo que se hace necesario encontrar soluciones.

El discurso y las prácticas de diseño y gestión de políticas de protección del tipo de cambio resurgieron recientemente ante la urgente necesidad de mitigar o evitar los efectos negativos que traen las corrientes de capital transfronterizas de corto plazo. El factor que ha propiciado la confrontación es la asimetría entre las políticas monetarias de las economías desarrolladas y las de las economías emergentes cuando estas últimas luchan por proteger el dinamismo de su crecimiento, que se ve perjudicado por las políticas de los países industriales orientadas a abaratar sus monedas y ganar competitividad cambiaria con el propósito de estimular su crecimiento por medio del impulso a sus exportaciones ${ }^{3}$.

\section{La gestión de los tipos de cambio}

En la década de 1970, las posturas neoliberales fundamentalistas de mercado defendieron a ultranza la liberalización de la cuenta de capital al argumentar que los flujos y su movilidad hacen posible que los países con pocos ahorros atraigan financiamiento para proyectos de inversión productiva, alienten la diversificación del riesgo de inversión, promuevan el comercio intertemporal y contribuyan al desarrollo de los mercados financieros (Ostry y otros, 2010a y 2010b). Con el tiempo, la evidencia ha demostrado que la liberalización del mercado de capitales en los países en desarrollo no ha estado asociada con el crecimiento económico y que tal asociación es más factible en naciones que han alcanzado un alto nivel de desarrollo institucional (Gallagher, 2010a). En general, los países emergentes

\footnotetext{
3 Sin embargo, Bergsten argumenta que la estrategia de relajamiento cuantitativo de la Reserva Federal no constituye una intervención de mercado, la que representa una curiosa manera de percibir los intereses nacionales (Bergsten y Gagnon, 2012).
} 
son más vulnerables a los efectos negativos de las corrientes de capital de corto plazo, ya que al ser menores a un año estos flujos de inversión solo buscan insertarse en economías con características político-económicas estables, simplemente para obtener el mayor rendimiento posible que puede aportar el acarreo de divisas. Cuando el diferencial que incentiva el acarreo se reduce o desaparece, estos capitales huyen súbitamente en busca de opciones de mayor rentabilidad en otros países.

Estas salidas súbitas de los flujos de capital tienden a complicar el manejo macroeconómico y aumentar los riesgos financieros. En la perspectiva macroeconómica, la preocupación reside en que las oleadas de capital causan presión al alza sobre el valor de la moneda nacional y provocan apreciaciones en los tipos de cambio nominal y real. A su vez, este hecho propicia que los productores nacionales menos competitivos en el mercado internacional se vean afectados al abaratarse las importaciones y encarecerse las exportaciones. Ello puede ocasionar un daño duradero en el sector exportador de la economía, aun y cuando las entradas de capital disminuyan o se reviertan.

Desde el punto de vista de la fragilidad financiera, la inquietud recae en que las excesivas entradas de capital pueden afectar la estabilidad financiera por el aumento del endeudamiento externo y una exposición excesiva a los riesgos cambiarios. Estos factores pueden inducir a fuertes expansiones del crédito interno y burbujas en el precio de los activos, con graves efectos adversos en caso de una reversión súbita de las entradas de capital (Ostry y otros, 2010a y 2010b; De Gregorio, 2010; Gallagher, 2010b; López-Mejía, 1999; Magud y Reinhart, 2006; Gallagher y Coelho, 2010). También hay que considerar los costos que implican una política de esterilización y las restricciones que pueden imponerse a la política fiscal. De ahí la importancia del reconocimiento que el Fondo Monetario Internacional (FMI) hace de la posible recurrencia a medidas que controlan las entradas de capital.

En febrero de 2010, el FMI reconoció que las regulaciones de las corrientes de capital transfronterizas pueden ser útiles y constituir una herramienta legítima de política macroeconómica (Ostry y otros, 2010a y 2010b; FMI, 2011a y 2011b). Posteriormente, en diciembre de 2012, el FMI (2012a y 2012b) postula oficialmente un nuevo "enfoque institucional" sobre la liberalización de la cuenta de capitales que las naciones pueden tener en cuenta para evitar y mitigar la volatilidad cambiaria y las crisis financieras. Esta es una postura altamente divergente de la aceptada en la era neoliberal de la década de 1970, que se acerca más a las posiciones postuladas por John Maynard Keynes y Harry Dexter en su debate entre 1941 y 1945 sobre el hecho de que los controles de capital deberían ser parte esencial para el buen funcionamiento del sistema monetario-financiero mundial (Gallagher, 2011a).

Para el FMI, la prioridad en la elaboración de políticas de gestión del tipo de cambio debe asentarse en medidas que fortalezcan a los países para absorber los flujos de capital (FMI, 2011b). El principio es que los países requieren estar mejor preparados para la afluencia de estos capitales y no para impedir su movilidad, lo que lleva a que se instrumenten reformas estructurales que incrementen la capacidad de los mercados financieros nacionales para procesar los flujos.

El FMI diferencia entre distintos tipos de medidas, dependiendo de si están o no orientadas a impedir el libre flujo de capitales. Las "medidas de gestión de los flujos de capital” que controlan el flujo de capitales son las más relevantes, debido a que pueden ser usadas como sustitutos de políticas macroeconómicas adecuadas y necesarias para economías en desarrollo, además de que pueden tener externalidades negativas para otros países (FMl, 2011b, pág. 6).

Las medidas de gestión de los flujos de capital, a su vez, se diferencian en dos tipos: las basadas en la residencia y las basadas en la no residencia. Las primeras, comúnmente denominadas controles de capital, afectan a la actividad financiera transfronteriza al discriminar sobre la base de la residencia. Estas medidas son más coyunturales en respuesta a las entradas de capital. Por su parte, las segundas son medidas prudenciales diseñadas para asegurar la fortaleza y la sanidad de las instituciones financieras, como coeficientes de capitalización, el coeficiente de préstamos a valor, los 
límites a posiciones abiertas en el mercado cambiario y los límites a hipotecas en moneda extranjera. En estas medidas basadas en la no residencia también se incluyen algunas que típicamente se aplican en el sector no financiero, como períodos mínimos de estadía o impuestos a algunos tipos de inversiones. Las medidas basadas en la no residencia no tienen los mismos efectos macroeconómicos y multilaterales de las que sí utilizan la residencia como parámetro, como limitar la apreciación de la moneda o reorientar los flujos hacia otros países. La diferencia fundamental entre estos dos tipos de medidas radica en si afectan directa o indirectamente la libre movilidad de los flujos de capital.

Para enfrentar los flujos, en primera instancia lo adecuado es recurrir a políticas macroeconómicas y, principalmente, permitir que el tipo de cambio se fortalezca, acumular reservas o reajustar el equilibrio entre las políticas fiscal y monetaria. La aplicación de medidas de gestión de los flujos de capital debe hacerse únicamente una vez que existan las condiciones macroeconómicas adecuadas, lo que implica que el tipo de cambio no esté subvaluado, que las reservas sean más que suficientes y que la economía esté sobrecalentada, lo que hace que no sea aconsejable bajar las tasas de interés. Las medidas de gestión de los flujos de capital deben ser complementarias de una política fiscal contractiva y tomar en cuenta los rezagos asociados a los efectos macroeconómicos de una consolidación fiscal. Para el FMI, la aplicación de las medidas de gestión de los flujos de capital debe tener baja prioridad a fin de no afectar a los otros países que participan en un marco de referencia multilateral.

Cabe reconocer que el cambio de posición del FMI ha sido el resultado de un amplio debate, pues hasta hace poco postular políticas de control de capital era ir en contra de la premisa básica neoclásica de que las economías emergentes deben liberar sus cuentas de capitales como parte de un proceso amplio de liberalización financiera necesario para estimular el crecimiento y la estabilidad económica (Gallagher, 2010b). No obstante, el FMl continúa sosteniendo su principio tradicional al insistir en que lo principal es evitar impedimentos a la libre movilidad del capital por el efecto negativo que pueda tener en los países generadores de estos fondos, generalmente los países industriales. Menos relevante es el costo en que pueden incurrir los países receptores para mantener esta posición, en general los países emergentes. Es en este contexto de debate teórico que en este trabajo se examina la postura de libre circulación de capitales que profesan y han practicado las autoridades mexicanas.

\section{Volatilidad cambiaria y política pública en México}

La apreciación del peso desde mediados de 2009 hasta abril de 2011 no llevó a que las autoridades mexicanas secundaran la postura que han tomado las autoridades de otros países de controlar los flujos especulativos. La perspectiva de las autoridades monetarias mexicanas, particularmente las del Banco de México y de la Secretaría de Hacienda y Crédito Público (SHCP), se aferra a descartar que para la economía mexicana la apreciación del peso sea un factor de preocupación y, en consecuencia, no se requiere responder con medidas de gestión cambiaria.

Se ha argumentado que el régimen de flotación cambiaria funciona apropiadamente para absorber choques del exterior. Además, existe la posición oficial de no usar el tipo de cambio como herramienta de política comercial. Lo que debe hacerse es cuidar la estabilidad, tener un manejo responsable de las finanzas públicas y ser prudentes en la toma de decisiones (Banco de México, 2013). Más relevante es considerar que los riesgos que tiene la economía mexicana provienen principalmente de la desaceleración del ritmo de crecimiento de los Estados Unidos y, en menor grado, de la incertidumbre fiscal de algunos países europeos. Más aún, se presume que la apreciación cambiaria responde a la solidez de los fundamentos de la economía por su bajo nivel inflacionario y 
por sus ventajas competitivas, como la ubicación geográfica, una base sólida de capacitación, y bajos costos de transporte y logística (Piz, 2011a y 2011b). Tampoco se acepta que la ventaja del sector exportador depende del tipo de cambio.

El Banco de México (BANXICO) y la Secretaría de Hacienda y Crédito Público han argumentado que las políticas basadas en medidas de gestión de los flujos de capital no tienen un efecto sostenible a mediano plazo. Más aún, se argumenta que los controles a los flujos de capital no son adecuados para México, dado que el país se encuentra en una etapa avanzada de profundización financiera. En el fondo, estas autoridades visualizan estos flujos de capital como una evidencia inconfundible del buen rumbo que lleva la economía mexicana como resultado de la gestión de las políticas públicas ${ }^{4}$. Pero el factor determinante de esta postura oficial es el blindaje con el que cuenta la economía mexicana para sortear las turbulencias internacionales, que se sustenta en la política de acumulación de reservas internacionales y en la línea de crédito aprobada por el FMI. Esta postura oficial ha sido fruto del fundamentalismo de mercado con que se maneja la economía mexicana desde finales de la década de 1980, que va en total congruencia con la posición del FMI de que los países deben recurrir a las políticas de administración cambiaria más para adecuar sus economías a recibir estos capitales que para impedir su entrada.

Estas posiciones de las autoridades no son compartidas por otros sectores. Buena parte del empresariado y de los productores nacionales sustentan posiciones discrepantes con una postura generalizada de que la fortaleza del dólar está provocando que los productos extranjeros sean cada vez más baratos en el mercado nacional y los productos de exportación, más caros. Diferentes organismos empresariales han exhortado a las autoridades a defender la competitividad de la industria y a evitar la apreciación de la moneda, ya que, en su opinión, una moneda demasiado fuerte provoca pérdida de competitividad y efectos negativos en las exportaciones de muchos sectores (Monroy, 2011).

Lo que ha sido evidente es que las posiciones de los dirigentes empresariales y las autoridades monetarias respecto de los efectos de la apreciación de la moneda nacional no son coincidentes, pero lo que complica el debate es que la apreciación del peso no parece ser una traba para que las exportaciones crezcan. Por tanto, conviene identificar los factores que pueden dar lugar a estas diferentes opiniones sobre el efecto del tipo de cambio nominal y del tipo de cambio real sobre la economía, pero, principalmente, del costo que tiene para México el recibir estos flujos de capital golondrina.

\section{La evolución del superpeso}

A partir de la crisis de 1994, la volatilidad del peso mexicano ha sido extraordinaria pese a que el país estuvo sujeto a diversos regímenes de política monetaria y cambiaria. En el gráfico 1 se observa que, desde el abandono del régimen de tipo de cambio completamente fijo de 12,50 pesos por dólar en 1976, la paridad nominal se ha movido con una tendencia de pérdida de valor a largo plazo. Entre 1976 y 1994, este fue el resultado de las devaluaciones instrumentadas con la lógica del régimen de tipo de cambio fijo pero ajustable. A partir de 1995, no obstante el giro hacia un régimen de libre flotación, la paridad entre el peso y el dólar ha mantenido la tendencia de depreciación a largo plazo en un marco de mayor volatilidad por apreciaciones y depreciaciones de corto plazo.

\footnotetext{
4 Estas posiciones contrastan con las del banco central de Australia, un país desarrollado que en el mismo período que México experimentó un considerable acarreo de divisas y, en consecuencia, una fuerte apreciación de su moneda. Dicho banco advierte que la fortaleza del dólar australiano ha creado altos riesgos para la economía, debido a que las empresas manufactureras han perdido competitividad, lo que ejerció efectos negativos en el empleo (The Economist, 2012, pág. 30).
} 
Gráfico 1

México: tipo de cambio nominal, 1976-2014

(En pesos por dólar)

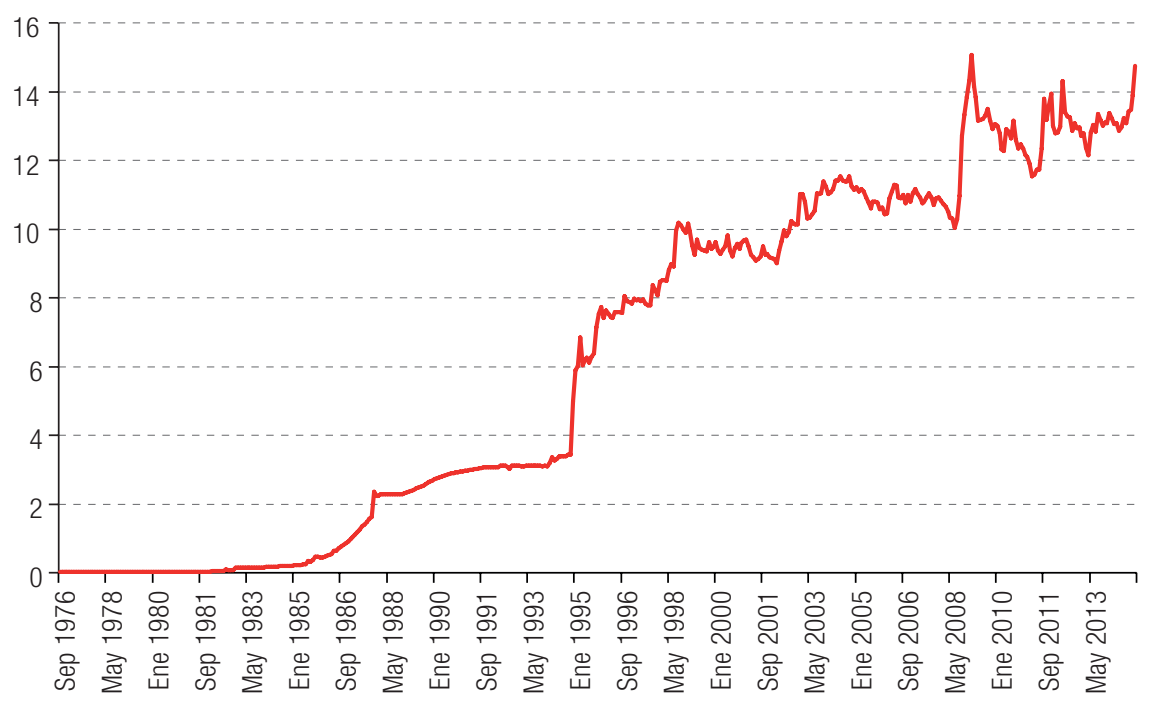

Fuente: Elaboración propia, sobre la base de datos del Banco de México.

La observación del gráfico 1 permite advertir que desde la crisis de 2008 el tipo de cambio nominal tuvo una fuerte apreciación: pasó de 15,06 pesos por dólar en febrero de 2009 a 11,52 en abril de 2011. Esta apreciación del 23,5\% ubica el valor de la moneda mexicana en el rango que tuvo a mediados de 2004, pero lo mantiene aún alejado de los niveles inferiores a 11 pesos por dólar que experimentó a mediados de 2008. Lo más que puede decirse es que esta apreciación ha servido para regresar el valor nominal de la moneda mexicana a la tendencia de largo plazo impuesta por el régimen de libre flotación. Analizar la problemática del tipo de cambio exclusivamente desde esta perspectiva puede dar a las autoridades mexicanas la razón de que el comportamiento del tipo de cambio no requiere de medidas de gestión.

La tendencia de largo plazo de los tipos de cambio nominal y real (véase el gráfico 2), donde se distinguen los diferentes períodos de sobrevaluación y subvaluación experimentados por el peso mexicano frente al dólar desde 1970, hace evidentes dos hechos. El primero es la divergencia de comportamientos que tienen estas dos tendencias: mientras el tipo de cambio nominal tiende a una depreciación persistente de largo plazo, el tipo de cambio real fluctúa cíclicamente entre apreciaciones y depreciaciones. El factor central de estas divergencias es el patrón de comportamiento de la inflación de México frente a la de los Estados Unidos.

El segundo hecho es que la economía mexicana ha funcionado fundamentalmente basada en un tipo de cambio sobrevaluado durante estos 40 años, salvo períodos cortos de subvaluación: de octubre de 1976 a junio de 1977; de marzo de 1982 a octubre de 1984; de julio de 1985 a julio de 1990; de enero de 1995 a enero de 1997; y durante septiembre y octubre de 1998. De finales de 1998 a 2012, la sobrevaluación fue persistente, aunque con ligeras variaciones en su grado de fortaleza.

Teóricamente, por tener una economía abierta con un modelo de crecimiento orientado hacia la promoción de las exportaciones, México debería mantener un tipo de cambio ligeramente subvaluado, que le proporcionaría un mayor grado de competitividad, lo cual fue aceptado como principio de la política cambiaria desde el Plan Nacional de Desarrollo Económico de Miguel de la Madrid Hurtado (1983-1988). Esta fue una posición congruente con los postulados del consenso de Washington (Williamson, 1990; Kuczynski y Williamson, 2003). Parece, entonces, que en lo referente al tipo de cambio, México ha remado constantemente a contracorriente, como explicaremos a continuación. 


\section{Gráfico 2}

México: tendencias del tipo de cambio real y nominal, 1970-2014

(En pesos mexicanos)

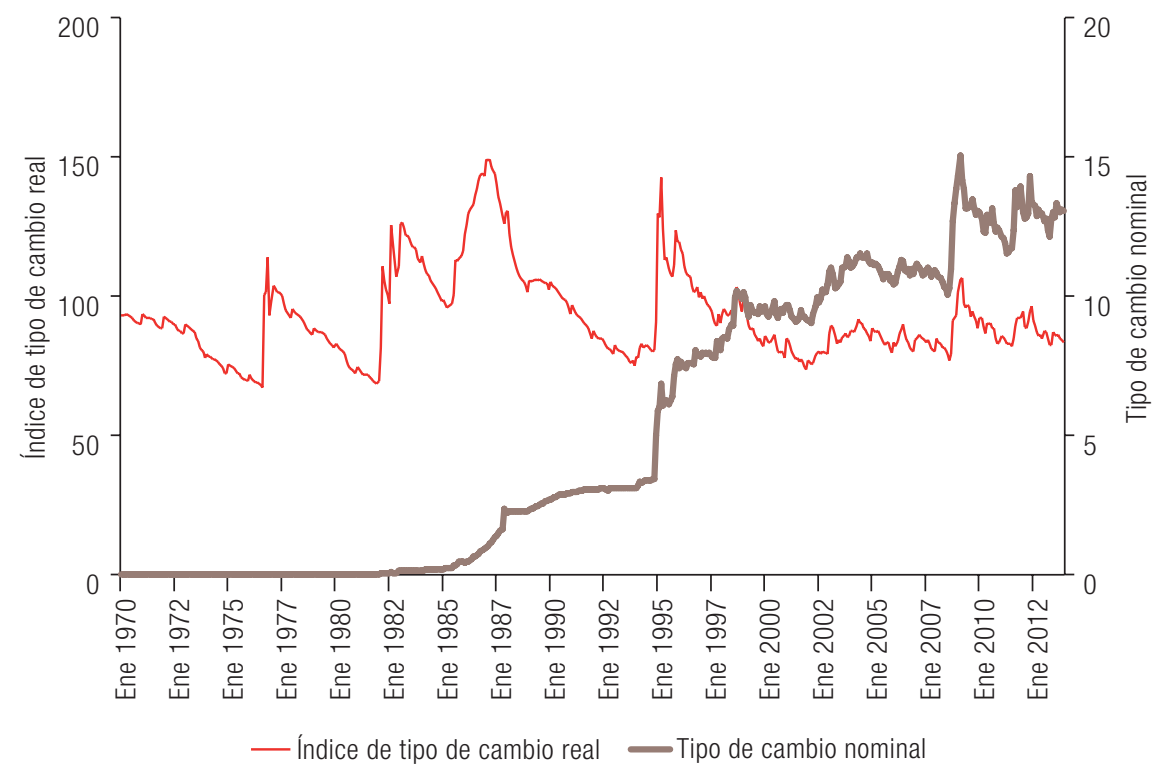

Fuente: Elaboración propia, sobre la base de datos del Banco de México.

En el gráfico 3 se presentan las variaciones en el grado de sobrevaluación y subvaluación de la moneda mexicana frente al dólar entre 1970 y 2012. Estos grados permiten analizar la dinámica del mercado cambiario sobre la base de la diferencia porcentual entre el tipo de cambio nominal y el tipo de cambio real a un año base específico. Los valores negativos indican una subvaluación de la moneda nacional con respecto al dólar y los valores positivos representan una sobrevaluación. Estos valores muestran el grado de desequilibrio en el que ha permanecido el tipo de cambio. De abril de 2009 a junio de 2012, la sobrevaluación mensual media fue del 7,2\% y en un período de mediano plazo (de enero de 2000 a febrero de 2012) este grado fue del 14,81\%, aunque llegó al 17,3\% en mayo de 2011. Estos grados de sobrevaluación son los que determinan el carácter de "superpeso" de la moneda nacional.

Cuando un tipo de cambio está sobrevaluado, en moneda nacional los productos extranjeros resultan más baratos que los productos nacionales, debido al ascenso del poder adquisitivo de la moneda extranjera respecto a la moneda local, lo cual incentiva una dinámica de compras en el exterior. Cuando un tipo de cambio está subvaluado, al descender el poder adquisitivo de la moneda local respecto de la moneda extranjera, los productos extranjeros resultan más costosos que los nacionales, lo que estimula el crecimiento de las exportaciones.

El aumento constante de los flujos de exportación e importación, sin embargo, demuestra que la sobrevaluación del peso mexicano no ha sido negativa para el éxito de la política exportadora. De hecho, México ha llegado a ser uno de los países más exportadores del mundo, al tiempo que dejaba de ser un país que exportaba principalmente productos del sector primario para convertirse en un exportador de manufacturas. La evidencia muestra que, en la etapa de apreciación cambiaria entre marzo de 2009 y marzo de 2012, las exportaciones mexicanas crecieron un 75\% y las importaciones, un $66,2 \%$. Desde cualquier perspectiva, estos datos apuntan a que la sobrevaluación del peso no tiene efectos negativos para las exportaciones mexicanas (Mold y Rozo, 2006; Rozo, 2009). 
Gráfico 3

México: subvaluación y sobrevaluación del peso mexicano, 1970-2014

(En porcentajes)

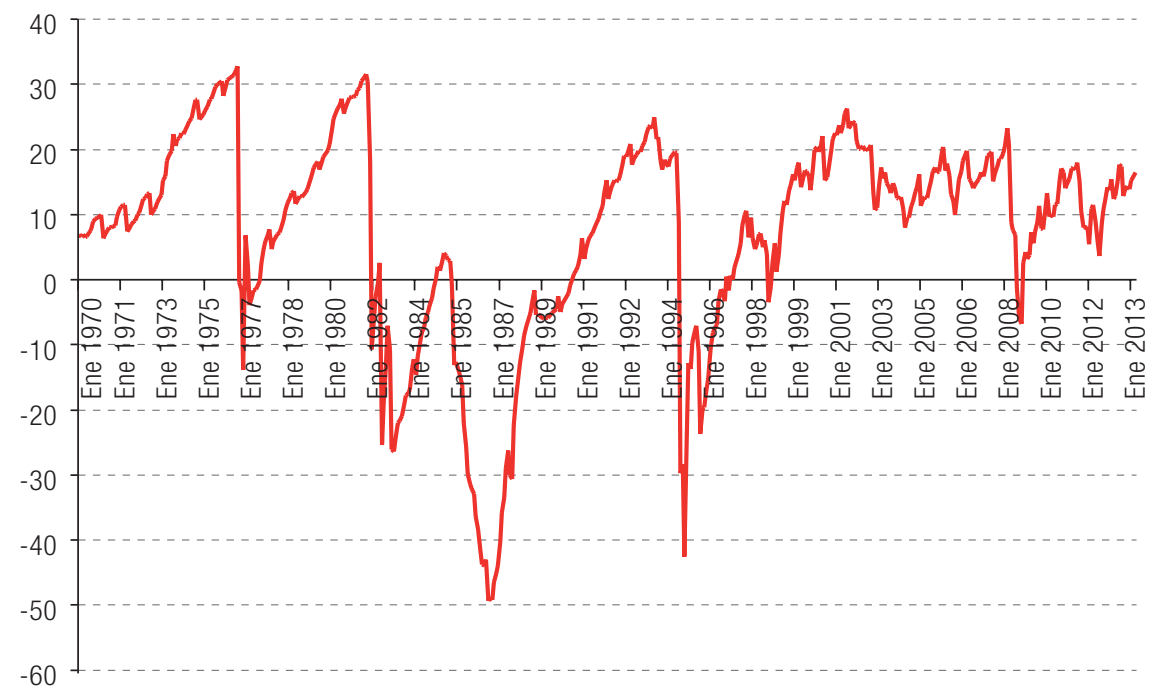

Fuente: Elaboración propia, sobre la base de datos del Banco de México.

Cabe resaltar de estas observaciones que en una economía muy dependiente de insumos importados, como la mexicana, un tipo de cambio sobrevaluado no necesariamente es negativo para las exportaciones La sobrevaluación conviene a la actividad exportadora, que es realizada sobre todo por empresas transnacionales y sobre la cual se sustenta el actual modelo de desarrollo de México. Este orden de cosas podría explicar la posición de las autoridades mexicanas de no alarmarse por la sobrevaluación cambiaria.

En consecuencia, ¿no debe ser motivo de preocupación la apreciación del tipo de cambio? El dilema es que la apreciación del tipo de cambio nominal que están experimentando las monedas de México y de otros países emergentes no es un simple desequilibrio temporal de la balanza comercial, sino el resultado de un acarreo mayúsculo y acelerado de capitales especulativos propiciado por una política deliberada y de largo plazo de los países industriales para acelerar el proceso de recuperación económica por medio de la actividad exportadora, como se muestra en la siguiente sección. Tal proceder ocurre sin consideración de los efectos negativos que ello pueda tener en la competitividad comercial y en las capacidades de crecimiento y desarrollo de las economías emergentes. Para contrarrestar estas presiones por tener divisas inversoras, las economías emergentes se han visto obligadas a recurrir a la acumulación de reservas internacionales en montos nunca antes experimentados. El dilema real que se tiene con la entrada de estos capitales especulativos, que implica mantener un nivel de reservas extraordinariamente elevado, es que se incurre en un costo alto sin que sean evidentes sus beneficios.

\section{Magnitud y rendimiento de los flujos de capital}

El acarreo de divisas hacia México es producto del atractivo rendimiento que tienen los instrumentos de deuda gubernamental. El diferencial que existe entre las tasas de interés secundarias de bonos gubernamentales mexicanos y la tasa de interés de bonos del Tesoro de los Estados Unidos es el factor central de estos flujos de capital especulativo. Para evidenciar dicho mecanismo, el 
rendimiento $(R)$ se puede medir mediante la formulación, en su versión más sencilla, de la condición de paridad de intereses:

$$
R=i-\left(i^{*}+(T C E-T C N) / T C N\right)
$$

donde $i$ representa la tasa de interés local, $i^{*}$ es la tasa de interés en el extranjero, TCE es el tipo de cambio esperado y $T C N$ el tipo de cambio nominal. Si $R$ es positivo, lo conveniente es invertir en la economía local; si es negativo, conviene más invertir en el extranjero. Cuando el rendimiento es 0 , resulta irrelevante en qué país se invierte, dado que la rentabilidad en ambos destinos es la misma. Para realizar este análisis de rentabilidad en la economía mexicana, se ha tomado la tasa de interés local de referencia de corto plazo, representada por la tasa de rendimiento de Certificados de la Tesorería (CETES) a 28 días, debido a la creciente demanda de este tipo de valores gubernamentales, mientras que la tasa de interés en el extranjero es la tasa efectiva de los fondos federales de los Estados Unidos, y el cambio en la paridad es referido por el tipo de cambio nominal -FIX - (peso por dólar) que publica el Banco de México. En el gráfico 4 se muestra el rendimiento mensual promedio de inicios de 2007 a 2013, calculado aplicando el concepto de la paridad de interés antes explicado.

Gráfico 4

México: evolución de la tasa de rendimiento, 2007-2014

(En porcentajes)

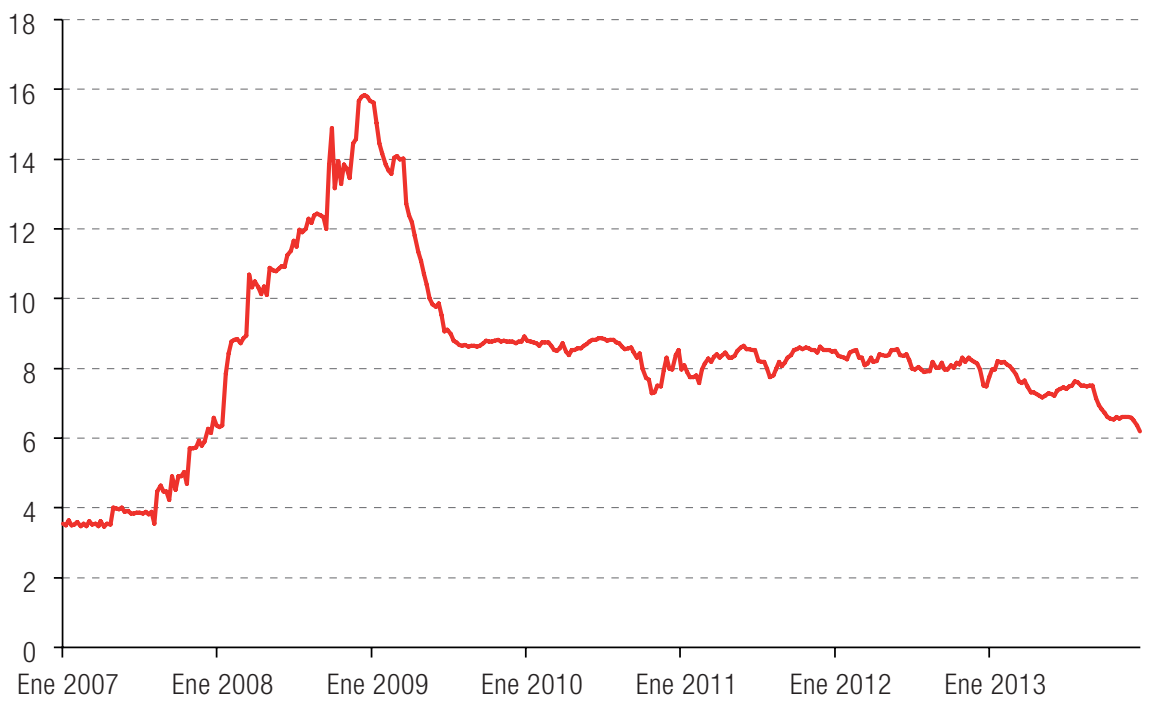

Fuente: Elaboración propia, sobre la base de datos del Banco de México.

La desaceleración de la economía de los Estados Unidos y la posterior crisis de las hipotecas de alto riesgo en 2008 obligaron a que la tasa efectiva de los fondos federales pasara del 5,25\% en enero de 2007 al 0,25\% en diciembre de 2008 y se mantuviera en ese nivel aún a mediados de 2015. Sin duda, este es un hecho que ha incentivado la fuga de capitales especulativos hacia mercados emergentes. En particular, en México encuentran un refugio adecuado, dada la política oficial de puertas abiertas y el alto rendimiento de la deuda gubernamental. De enero de 2007 a diciembre de 2008, el descenso de la tasa efectiva de los fondos federales de los Estados Unidos elevó el rendimiento en México a su máximo nivel: el 18 de diciembre de 2008 alcanzó el 15,84\% en instrumentos de deuda de corto plazo. Las estimaciones hechas con esta lógica de inversión de corto plazo permiten observar que durante 2013 la tasa de rendimiento promedio de los instrumentos de deuda mexicanos de corto plazo fue del 7,29\%, una reducción significativa pero que llegaba 
a aproximadamente el triple del rendimiento que se obtenía en las economías desarrolladas, que apenas alcanzaba al 2,5\%, según datos del Instituto Nacional de Estadística y Geografía (INEGl).

El mayor rendimiento en México es lo que propicia la considerable entrada de inversión de cartera, como se aprecia en el gráfico 5. Entre 2006 y 2008, estas entradas de capital eran erráticas y no tenían una tendencia definida, pero a partir de 2009 se observa una tendencia inequívoca de crecimiento acelerado. A finales de 2008 , cuando comienza la primera fase del relajamiento cuantitativo (de noviembre de 2008 a marzo de 2010), el acarreo de divisas comienza su marcha y se consolida con la segunda fase del programa (de noviembre de 2010 a junio de 2011). Con la aplicación de la tercera fase acordada por la Reserva Federal el 11 de septiembre de 2012, se mantiene el elevado volumen de flujos de capital especulativo (véase el gráfico 6). Al cierre de 2008, los títulos gubernamentales en poder de no residentes llegaban a 251.114 millones de pesos -el 11,7\% del total-, pero para finales de 2014 sumaban 1,53 billones de pesos, monto equivalente al 38\% del total. Estos flujos manifiestan, además, un cambio estructural en la composición de la inversión extranjera en México. Hasta 2009, los flujos de entrada de inversión extranjera directa (IED) fueron superiores a los flujos de inversión de cartera: los primeros alcanzaron los 17.331 millones de dólares, mientras que los segundos llegaron a 15.261 millones de dólares. La inversión de cartera pasó de representar el 29,5\% de la inversión extranjera total en 2007 al 80,8\% en 2012. No obstante la aprobación de las reformas estructurales al inicio de la presidencia de Enrique Peña Nieto, la entrada de IED en el país fue de 38.285 millones de dólares en 2013 - el 39,8\% de la inversión extranjera total - , en tanto la inversión de cartera sumó 50.359 millones de dólares, es decir, el 60,8\%.

\section{Gráfico 5}

México: comparación entre la inversión de cartera y la tasa de los fondos federales de los Estados Unidos, 2006-2013

(En dólares y porcentajes)

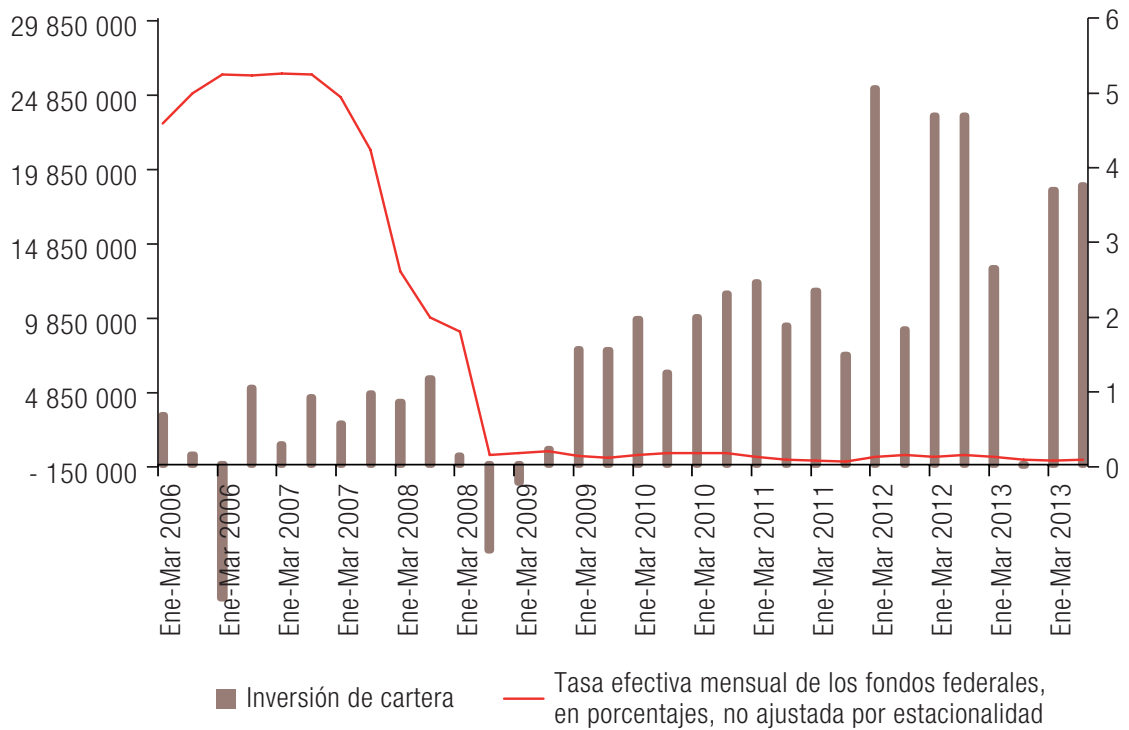

Fuente: Elaboración propia, sobre la base de datos del Banco de México y de la Reserva Federal. 
Gráfico 6

México: tenencia de valores gubernamentales, 2006-2014

(En billones de pesos)

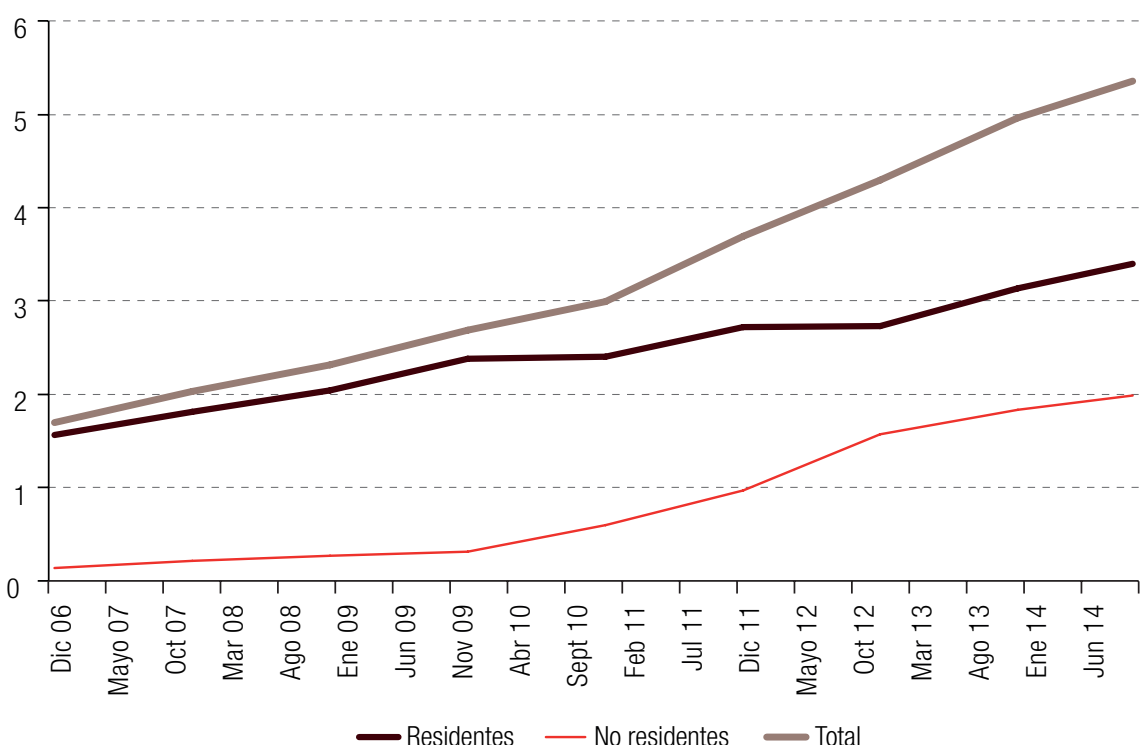

Fuente: Elaboración propia, sobre la base de datos del Banco de México.

No debe sorprender, entonces, que la tasa efectiva de los fondos federales de los Estados Unidos y las corrientes de inversión de corto plazo hacia la economía mexicana hayan tenido una correlación negativa de 2006 a 2013. Esta relación negativa implica que, cuando la tasa de interés de los Estados Unidos desciende, los flujos de inversión extranjera de corto plazo crecen, lo que corrobora que, mientras la economía estadounidense mantenga una política monetaria ultraexpansiva que permita una tasa de interés mínima, las condiciones de rentabilidad en México seguirán incentivando el acarreo de capitales. La rentabilidad segura y alta es el factor que produce este flujo de capitales hacia México y no los fundamentos sólidos de la economía, como repetidamente aseguran las autoridades mexicanas. También significa que, cuando la Reserva Federal incremente su tasa de interés, los capitales estacionados en México y en otros mercados emergentes emigrarán aceleradamente hacia los Estados Unidos, como ocurrió a principios de 2015, cuando parecía inminente que la Reserva Federal aumentaría la tasa de interés hacia mediados de año. Desde entonces, la economía de los Estados Unidos parece no encontrar el camino hacia una recuperación sólida y fuerte, como tampoco lo encuentran el resto de los países industriales, por lo que nos atrevemos a postular que el inicio hacia la normalización de la política monetaria de los Estados Unidos tendrá que esperar.

Sin duda, desde 2010 México se ha convertido en un mercado altamente atractivo para el estacionamiento de capitales especulativos, como consecuencia de una política pública que incentiva su entrada al ofrecer jugosas y fáciles ganancias, y de una posición abierta y explícita de las autoridades de no imponer restricciones a su ingreso ni a su permanencia en el país.

\section{El costo del blindaje financiero}

Hace años las reservas internacionales servían para administrar el tipo de cambio que resultaba de las transacciones de oferta y demanda en la cuenta corriente, pero esta lógica ha girado hacia la administración del tipo de cambio resultante de las transacciones de oferta y demanda provenientes de la cuenta de capitales. Se manifiesta así la preponderancia de la globalización financiera sobre la 
comercial, y se percibe inequívocamente lo que Peter Drucker (1986) denominó el desacoplamiento entre la economía real y la financiera.

El punto de partida en una gestión estratégica de las reservas es reconocer que México no se ha sumado a la lista de economías preocupadas por los efectos que tienen los flujos de capital transfronterizos de corto plazo. Al negarse a gestionar el tipo de cambio, las autoridades mexicanas han defendido la política de flexibilidad cambiaria como la única opción válida y la han reforzado con una política preventiva de acumulación de reservas y de créditos del FMI. La opción de política pública ha sido la de blindar la economía contra turbulencias que puedan ocurrir por la permanencia y salida de capitales. La estrategia de blindar la economía mexicana se inició en abril de 2009, cuando el Banco de México solicitó al FMI la aprobación de una Línea de Crédito Flexible (LCF) por 31.528 millones de derechos especiales de giro (DEG), aproximadamente 47.000 millones de dólares (el 1.000\% de la cuota de México en el FMI), por un período de 12 meses. En marzo de 2010, se renovó nuevamente esta LCF con el FMl por un plazo adicional de 12 meses, aun cuando México no tuvo necesidad de usar los recursos disponibles. Se consideró que la LCF cumplió con el objetivo de generar confianza en los mercados financieros (Comisión de Cambios, 2010a, 2010b y 2010c). En enero de 2011, se aprobó una vez más la LCF, pero esta vez con vigencia a dos años y por 72.000 millones de dólares (el $1.500 \%$ de la cuota). Estos cambios obedecieron a la mayor incertidumbre presente en la actividad económica internacional (Comisión de Cambios, 2011). En ese momento, no se podía hacer oídos sordos a la apreciación del peso causada por la entrada de flujos especulativos. Esta política de acumulación de reservas internacionales ha llevado a que los activos de reservas oficiales sumen la histórica cantidad de 195.682 millones de dólares al cierre de 2014, que, al complementarse con la LCF, significan un nivel de blindaje financiero de 270.000 millones de dólares.

El dilema con esta línea de acción es que tiene costos altos y poco transparentes, y a los cuales se hace poca referencia. Las autoridades monetarias prefieren enfatizar que la economía mexicana se encuentra bien preparada para responder con la liquidez necesaria para mitigar el choque que podría provocar una súbita fuga de capitales con un monto de reservas que suben constantemente, pero no se menciona el costo que implica esta estrategia. Si las reservas son tratadas simplemente como un activo de cartera, sin considerar su financiamiento o las obligaciones correspondientes, su acumulación se toma como una ganancia neta. Pero al abordar la cuestión del financiamiento, el resultado financiero neto de mantener reservas puede representar una pérdida para el país (Nugée, 2004; Rodrik, 2006).

Existen al menos cuatro tipos de costos en la acumulación de reservas. El costo de oportunidad, el costo financiero o de esterilización, el costo de balance y el costo por falta de incentivos (Flores, 2010; Santaella, 2010; Cruz, 2006). Rodrik argumenta la existencia de un costo de oportunidad social que tiene el capital público y que debe ser el que se toma en cuenta al examinar el costo que puede entrañar la política de blindaje de una economía por la acumulación de activos líquidos en la forma de reservas internacionales. Con esta lógica, Rodrik estimó que en el período 1995-2004 el costo de esta acumulación de reservas pasó del 0,002\% a casi el 1\% del PIB de los países en desarrollo (Rodrik, 2006).

Para calcular el costo de acumular reservas en México, hemos recurrido a estimar los costos financiero y de oportunidad. El costo financiero se toma como el diferencial entre el rendimiento de los activos, en este caso las reservas internacionales brutas, y el costo de los pasivos representados por la base monetaria y por depósitos de regulación monetaria, como se aprecia en el cuadro 1. Por su parte, el costo de oportunidad se toma como el diferencial entre el rendimiento de los activos y el costo de la deuda externa del Gobierno Federal, como se presenta en el cuadro 2. Para elaborar el análisis de los costos se deben tener niveles apropiados de rendimiento. Según datos de Santaella (2010), los activos de reserva internacional proporcionaron un rendimiento del 0,9\% en 2009, mientras que los pasivos tuvieron un rendimiento del 5,75\%. A simple vista, se vislumbra un marcado diferencial entre estas tasas cercano a 485 puntos base. 


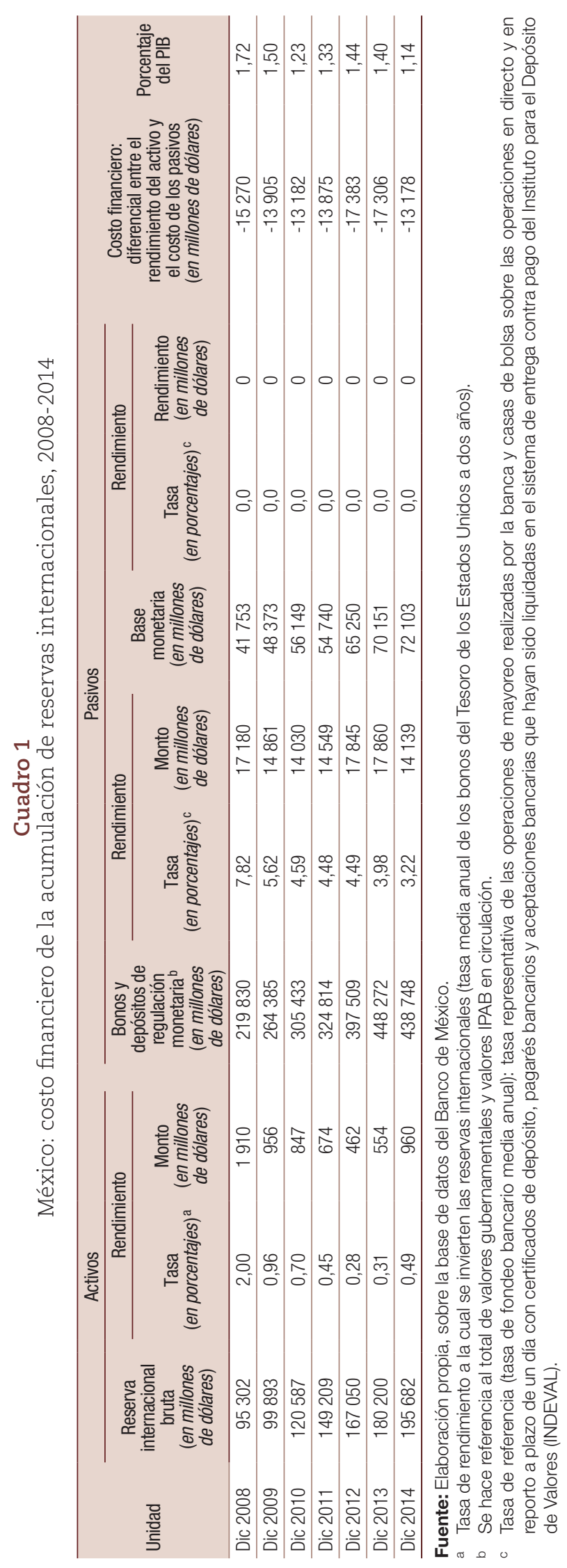




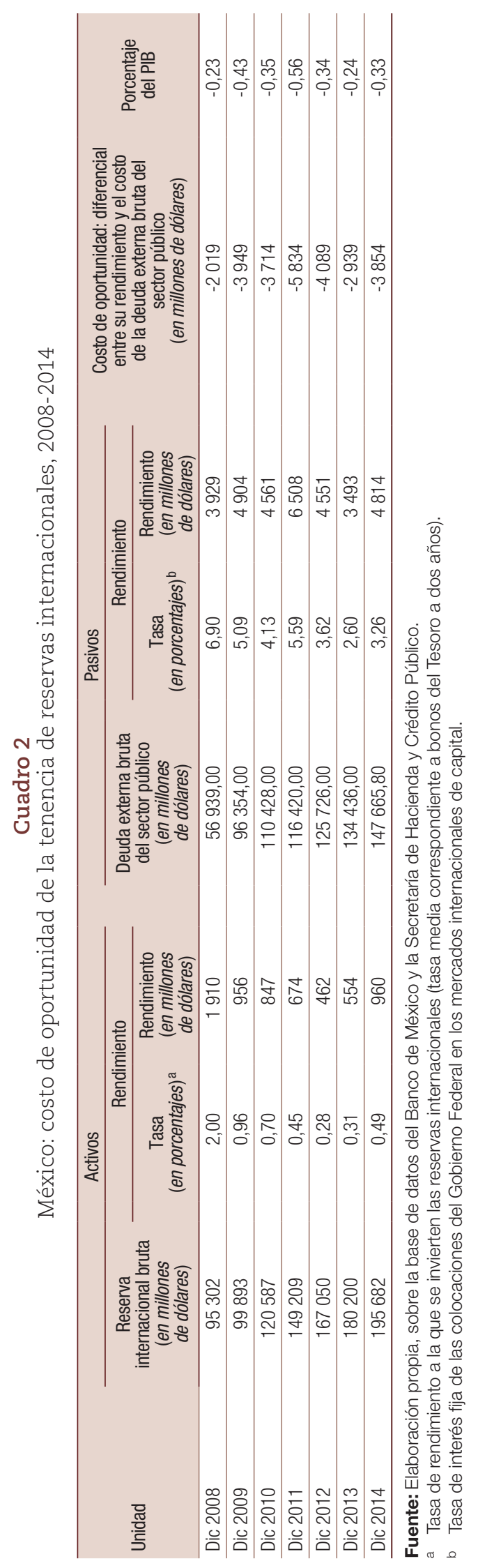


El rendimiento de los activos de las reservas internacionales se reduce entre 2008 y 2012 como resultado del extraordinario descenso de la tasa de descuento de los instrumentos de primer orden en los que son invertidas las reservas internacionales, como los bonos del Tesoro de los Estados Unidos. En contraste, los pasivos, aunque muestran un descenso a lo largo del mismo período, tienen un rendimiento mucho mayor. A primera vista es evidente que las autoridades mexicanas han pagado un rendimiento mayor por financiar las reservas que el rendimiento que obtienen por ellas y que este costo creció con el tiempo al pasar de 13.905 millones de dólares en 2009 a 17.306 millones en 2013, aunque se redujo en 2014.

El comportamiento del costo de oportunidad es menos homogéneo, como se aprecia en el cuadro 2, debido a que en 2008 los activos tuvieron un rendimiento alto dadas las tasas de interés positivas que aún existían en los mercados financieros, pero que posteriormente bajaron hasta el 0,31\% en 2013, lo que hizo que estos rendimientos se redujeran paulatinamente de 1.919 millones de dólares en 2008 a 554 millones de dólares en 2013, aunque en 2014 se obtuvo un rendimiento mayor.

También el rendimiento de los pasivos se vio afectado: la tasa bajó del 6,9\% en 2008 al 3,26\% en 2014; no obstante, el costo de estos pasivos pasó de 3.929 millones de dólares a 5.834 millones entre 2008 y 2011. Este crecimiento constante del costo de oportunidad de mantener reservas responde a que prácticamente estas se duplicaron entre 2008 y 2011. La tendencia de este costo fue a la baja en los siguientes años hasta ubicarse en 2.939 millones de dólares en 2013 como consecuencia de la fuerte caída de la tasa de rendimiento, pero experimentó un repunte en 2014. El hecho relevante es que el costo de oportunidad también ha crecido paulatinamente durante estos años, aunque en montos absolutos es mucho menor que el costo financiero. Estas diferencias se captan cabalmente al calcular la proporción de estos costos con relación al producto interno bruto (PIB) (véase el cuadro 3). En estos años el costo financiero promedio anual equivalió al 1,39\% del PIB, mientras que el costo de oportunidad promedio anual fue del 0,35\% del PIB.

Cuadro 3

México: costo total de las reservas internacionales como proporción del PIB, 2008-2014

(En porcentajes)

\begin{tabular}{lcccc}
\hline Año & Financiero & Oportunidad & LCF & Total \\
\hline 2008 & 1,72 & 0,23 & & 1,95 \\
\hline 2009 & 1,50 & 0,43 & 0,12 & 2,05 \\
\hline 2010 & 1,23 & 0,35 & 0,10 & 1,68 \\
\hline 2011 & 1,33 & 0,56 & 0,10 & 1,99 \\
\hline 2012 & 1,44 & 0,34 & 0,09 & 1,87 \\
\hline 2013 & 1,40 & 0,24 & 0,09 & 1,73 \\
\hline 2014 & 1,14 & 0,33 & 0,09 & 1,56 \\
\hline Promedio & 1,39 & 0,35 & 0,10 & 1,83 \\
\hline
\end{tabular}

Fuente: Elaboración propia.

Para lograr una aproximación más exacta al costo de mantener este nivel de reservas es necesario añadir a estos costos - financiero y de oportunidad - el costo por la contratación de la LCF, que anualmente tiene una prima de 1.080 millones de dólares. Por tanto, el costo total del blindaje financiero varió entre el 2,05\% y el 1,57\% del PIB, y promedió en estos seis años el 1,83\% del PIB.

Al igual que Rodrik, consideramos que este nivel de costos es muy alto, independientemente de la medida que se use. Solo hay que tomar en cuenta que este monto es muy superior a cualquiera de los programas antipobreza que se hayan implementado en países en desarrollo. Por ejemplo, el programa Progresa en México apenas tuvo un costo aproximado del 0,02\% del PIB en 2001, su último año de funcionamiento, y el programa Oportunidades, que lo reemplazó, tuvo un costo aproximado del 
0,42\% del PIB de 2010. En 2011, el blindaje financiero por acumulación de reservas internacionales equivalió aproximadamente a diez veces el presupuesto asignado al programa Oportunidades y, por si fuera poco, equivale a cuatro veces el presupuesto asignado a la Secretaría de Desarrollo Social, que tiene la tarea de luchar contra la pobreza. Rodrik concluye que las naciones en desarrollo están pagando un precio muy alto para respetar las reglas de la globalización financiera (2006, pág. 9).

Lo más grave de esta situación es la falta de evidencia sobre los supuestos beneficios de este endeudamiento de corto plazo. Se supone que este endeudamiento debe inducir a una mejor intermediación financiera, a promover mayor inversión local y a crear mayores oportunidades de riesgo compartido, pero ello no parece ocurrir si se considera el bajo nivel de la cartera crediticia bancaria, que creció del 19\% al 27\% del PIB entre 2000 y 2014 (CNBV, 2014, pág. 16). En consecuencia, no parece tener sentido una política de acumulación de reservas para enfrentar la acumulación de pasivos líquidos de corto plazo cuyo principal beneficio aparentemente es el alargamiento del plazo de vencimiento de la deuda, que ha permitido que el horizonte de liquidación de cerca del $80 \%$ de la deuda sea superior a un año.

Una política más apropiada y mucho menos costosa sería la de optar por una reducción de la exposición a deuda de corto plazo, tal y como el propio FMl finalmente ha reconocido, sobre todo cuando se sabe que, hoy por hoy, los niveles de las reservas internaciones de México rebasan por mucho los indicadores de suficiencia basados en comercio, deuda y dinero. La razón entre la reserva internacional neta y las importaciones se ubica en el 40\%, cuando en teoría la razón tradicional equivale a una proporción del $25 \%$, lo que equivale a tres meses de importaciones. De la misma forma, la regla de Guidotti-Greenspan sobre el nivel de las reservas internacionales, que postula que los países deben mantener reservas líquidas iguales a sus pasivos externos que vencen dentro de un año (Rodrik, 2006, pág. 5), recomendaría tener solo el 60\% de las reservas actuales.

\section{Conclusiones}

La evidencia es inequívoca respecto de que la crisis mundial originada por los excesos del sector hipotecario de los Estados Unidos ha llevado a prácticas de política económica nacionales incongruentes con los requerimientos de estabilidad global. El alto desempleo y el bajo nivel de la demanda agregada en los países industriales han llevado a un relajamiento de sus políticas monetarias impensable en condiciones normales, pero hecho realidad por las condiciones de penuria vividas en este lustro reciente del siglo XXI. El resultado de estas políticas de laxitud monetaria ha sido el establecimiento de un ambiente de volatilidad de los tipos de cambio por el acarreo de divisas, que se ha propagado entre países industriales y países en desarrollo, situación que ha llevado a lo que metafóricamente se denomina "una guerra de divisas". Lo que evitó esta guerra y ha dado oportunidad de reducir las tensiones es el reconocimiento por parte del FMI de que en las condiciones actuales de la economía mundial algunas prácticas de gestión de los flujos de capital son aceptables y positivas para la estabilidad de los mercados emergentes.

Si bien México ha sido uno de los países más afectados por este acarreo de divisas y por el efecto que ello tiene en apreciar la divisa nacional, sus autoridades han descartado totalmente el uso de políticas de administración cambiaria, como sí ha instrumentado un buen número de economías emergentes. En parte, esto ha sido el resultado del fundamentalismo de mercado con que se maneja la economía mexicana desde finales de la década de 1980, que es totalmente congruente con la posición tradicional del FMI de que los países deben recurrir a las políticas de gestión de flujos más para adecuar sus economías a recibir estos capitales que para impedir su entrada. Esta actitud oficial también es consecuencia del limitado efecto que la apreciación del peso mexicano tiene en la dinámica exportadora. 
Lo que no queda muy claro es cuál es el beneficio de la entrada y permanencia de estos capitales de corto plazo para la economía mexicana. Más claro es que esta política de acumulación de reservas tiene un costo anual para los mexicanos que en promedio se aproxima al $2 \%$ del PIB de cada uno de los años del período 2009-2014. Bajo cualquier estándar de medida, este parece un costo muy elevado para un evento que en apariencia resulta poco probable, como la salida súbita de esos capitales, si se toman en consideración las condiciones de montos y los tiempos previstos para la normalización de la política monetaria de la Reserva Federal. Parafraseando el planteamiento de Rodrik, concluimos que México está pagando un precio muy alto para jugar según las reglas impuestas por la globalización financiera.

\section{Bibliografía}

Banco de México (2013), Reporte sobre el sistema financiero, Ciudad de México, septiembre. (2010), "Reporte sobre el sistema financiero. Junio de 2010", Ciudad de México [en línea] http://www. banxico.org.mx/publicaciones-y-discursos/publicaciones/informes-periodicos/reporte-sf/\%7BDC37ABCB26F0-020D-145B-5CF397D62E68\%7D.pdf.

Bergsten, C. F. y J. E. Gagnon (2012), "Currency manipulation, the US economy, and the global economic order", Policy Brief, N ${ }^{\circ}$ PB12-25, Washington, D.C., Peterson Institute of International Economics.

Brunnermeier, M. K., S. Nagel y L. H. Pedersen (2008), "Carry trade and currency crashes", NBER Working Paper, № 14473, Cambridge, Massachusetts, Oficina Nacional de Investigaciones Económicas.

Burnside, C., M. S. Eichenbaum y S. Rebelo (2011), "Carry trade and momentum in currency markets", NBER Working Paper, № 16942, Cambridge, Massachusetts, Oficina Nacional de Investigaciones Económicas.

Calvo, G. y C. Reinhart (2000), "Fear of floating", NBER Working Paper, № 7993, Cambridge, Massachusetts, National Bureau of Economic Research (NBER).

Clarida, R., J. Davis y N. Pedersen (2009), "Currency carry trade regimes: beyond the Fama regression", NBER Working Paper, Nㅜ 15523, Cambridge, Massachusetts, Oficina Nacional de Investigaciones Económicas.

CNBV (Comisión Nacional Bancaria y de Valores) (2014), Ahorro financiero y financiamiento en México. Cifras a junio 2014, Ciudad de México.

Comisión de Cambios (2011), "El director ejecutivo del FMl aprobó hoy la línea de crédito flexible de alrededor de 72 mil millones de dólares para México por dos años", Ciudad de México.

(2010a), "La Comisión de Cambios anuncia que se subastarán mensualmente opciones para vender dólares al Banco de México", Comunicado, Ciudad de México [en línea] http://calderon.presidencia. gob.mx/2010/02/la-comision-de-cambios-anuncia-que-se-subastaran-mensualmente-opciones-paravender-dolares-al-banco-de-mexico/.

(2010b), "Circular 8/2010. Asunto: subastas para la celebración de opciones de venta de dólares de los Estados Unidos de América", Ciudad de México, Banco de México.

(2010c), "El Fondo Monetario Internacional renovó formalmente la línea de crédito flexible que tiene México", Comunicado de Prensa, Ciudad de México, Banco de México.

Cruz, M. (2006), "¿Pueden las reservas internacionales contribuir al crecimiento económico?, Economía UNAM, N 8, vol. 3, Ciudad de México, Universidad Nacional Autónoma de México.

De Gregorio, J. (2010), "Regulación macroprudencial, estabilidad financiera y flujos de capital", Documentos de Política Económica, № 37, Santiago, Banco Central de Chile.

Dornbusch, R. (1976), "Expectations and exchange rate dynamics", Journal of Political Economy, vol. 84, Nㅜ 6.

Drucker, P. (1986), "The changed world economy", Foreign Affairs, vol. 64, № 4.

Engel, C. (1996), "The forward discount anomaly and the risk premium: a survey of recent evidence", Journal of Empirical Finance, vol. 3, No 2, Amsterdam, Elsevier.

Fama, E. F. (1984), "Forward and spot exchange rates", Journal of Monetary Economics, vol. 14, № 3, Amsterdam, Elsevier.

Ffrench-Davis, R. (2010), "Macroeconomía para el desarrollo, desde el 'financierismo' al 'productivismo'”, Revista CEPAL, № 102 (LC/G.2468-P), Santiago, Comisión Económica para América Latina y el Caribe (CEPAL).

Flores, L. A. (2010), "Costos de altas reservas internacionales”, El Economista [en línea] http://eleconomista. com.mx/mercados-estadisticas/2010/06/29/costos-altas-reservas-internacionales. 
FMI (Fondo Monetario Internacional) (2012a), "Liberalizing capital flows and managing outflows", Policy Papers, Washington, D.C., marzo.

(2012b), "The liberalization and management of capital flows: an institutional view", Policy Papers, Washington D.C., noviembre.

_ (2011a), "Statement by the Managing Director on recent experiences in managing capital inflows. Crosscutting themes and possible policy framework", Washington, D.C., marzo.

(2011b), "Recent experiences in managing capital inflows, cross-cutting themes and possible policy framework", Policy Paper, Washington, D.C., febrero.

Frankel, J. (2003), "Experience of and lessons from exchange rates regimes in emerging economies", NBER Working Paper, № 10032, Cambridge, Massachusetts, Oficina Nacional de Investigaciones Económicas.

Gallagher, K. (2011a), "Regaining control? Capital controls and the global financial crisis", PERI Working Paper, № 250, Amherst, Massachusetts, Instituto de Investigación en Economía Política.

(2011b), "Reforming United States trade and investment treaties for financial stability: the case of capital controls", Investment Treaty News, Art. 3, № 3, Instituto Internacional para el Desarrollo Sostenible.

(2010a), "Control that capital", Foreign Policy [en línea] http://www.ase.tufts.edu/gdae/Pubs/rp/ GallagherFPCapControl.pdf.

(2010b), "Policy space to prevent and mitigate financial crises in trade and investment agreements", G-24 Discussion Paper Series, №58, Nueva York, Naciones Unidas.

Gallagher, K. y B. Coelho (2010), "Capital controls and 21st century financial crises: evidence from Colombia and Thailand", PERI Working Paper, № 213, Amherst, Massachusetts, Instituto de Investigación en Economía Política.

Jordá, Ó. y A. M. Taylor (2009), "The carry trade and fundamentals: nothing to fear but fear itself", NBER Working Paper, № 15518, Cambridge, Massachusetts, Oficina Nacional de Investigaciones Económicas.

Keynes, J. M. (2003), Teoría general de la ocupación, el interés y el dinero, Ciudad de México, Fondo de Cultura Económica.

Kuczynski, P. y J. Williamson (2003), After the Washington Consensus. Restarting Growth and Reform in Latin America, Washington, D.C., Instituto de Economía Internacional.

López-Mejía, A. (1999), "Grandes flujos de capital: causas, consecuencias y opciones de política", Finanzas y Desarrollo, Washington, D.C., Fondo Monetario Internacional (FMI), septiembre.

Magud, N. y C. Reinhart (2006), "Capital controls: an evaluation", NBER Working Paper, Nº, 11973, Cambridge, Massachusetts, Oficina Nacional de Investigaciones Económicas.

Mold, A. y C. A. Rozo (2006), "Liberalization, growth and welfare: the Maquilizacion of the Mexican economy", Trade, Growth, and Inequality in the Era of Globalization, K. Sharma y O. Morrissey (eds.), Londres, Routledge.

Monroy, M. (2011), "Industriales piden frenar al súper peso", Expansión, 21 de enero [en línea] http://www. cnnexpansion.com/economia/2011/01/21/Industriales-piden-frenar-al-súper-peso.

Nugée, J. (2004), "Manejo de reservas de oro y de divisas", Ensayos, № 71, Ciudad de México, Centro de Estudios Monetarios Latinoamericanos (CEMLA).

Ostry, J. y otros (2010a), "Capital inflows: the role of controls", IMF Staff Position Note, N SPN/10/04, Washington, D.C., Fondo Monetario Internacional (FMI). (2010b), "Entradas de capital: el papel de los controles", Revista de Economía Institucional, vol. 12, № 23.

Pérez, C. (2010), "Peligro: guerra de divisas", El País, 10 de octubre.

Piz, V. F. (2011a), "Apreciación del tipo de cambio, manejable", El Financiero, 7 de abril. (2011b), "México, imán de dólares", El Financiero, 27 de abril.

Rodrik, D. (2010), "The end of an era in finance" [en línea] http://www.project-syndicate.org/commentary/ rodrik41/English.

(2006), "The social cost of foreign exchange reserves", NBER Working Paper, № 11952, Cambridge, Massachusetts, Oficina Nacional de Investigaciones Económicas.

Rozo, C. A. (2009), "Apertura, tratados de libre comercio y expectativas frustradas de crecimiento", Fin de época: de la integración tradicional al regionalismo estratégico, A. Guerra-Borges (coord.), Ciudad de México, Siglo XXI.

Santaella, J. (2010), "Manejo de reservas internacionales y mercado cambiario", Ciudad de México [en línea] http://observatorio.azc.uam.mx/pdf/CBM_8_6_2010_8.pdf.

Stiglitz, J. (2010), "No es momento para una guerra comercial", El País, 2 de mayo [en línea] http://elpais. com/diario/2010/05/02/negocio/1272806074_850215.html.

The Economist (2012), "Hitched to the China wagon", 25 de agosto.

Williamson, J. (1990), "What Washington means by policy reform", Latin American Adjustment: How Much has Happened?, J. Williamson (ed.), Washington, D.C., Instituto de Economía Internacional. 